Article

\title{
Prefrontal Asymmetry during Cognitive Tasks and Its Relationship with Suicide Ideation in Major Depressive Disorder: An fNIRS Study
}

\author{
Seung Yeon Baik ${ }^{1}$, Jeong-Youn Kim ${ }^{1}{ }^{\mathbb{D}}$, Jongkwan Choi ${ }^{2}{ }^{\mathbb{D}}$, Ji Yeong Baek ${ }^{2}$, Yeonsoo Park ${ }^{1}$, \\ Yourim Kim ${ }^{1}$, Minjee Jung ${ }^{1}$ and Seung-Hwan Lee ${ }^{1,3, *(1)}$ \\ 1 Clinical Emotion and Cognition Research Laboratory, Inje University, Goyang 411-706, Korea; \\ sybaik91@gmail.com \\ 2 OBELAB Inc., Seoul 06211, Korea \\ 3 Department of Psychiatry, Inje University, Ilsan Paik Hospital, Goyang 411-706, Korea \\ * Correspondence: lshpss@hanmail.net; Tel.: +82-31-910-7260; Fax: +82-31-910-7268
}

Received: 7 October 2019; Accepted: 13 November 2019; Published: 15 November 2019

\begin{abstract}
Reduced oxygenation changes in the prefrontal cortex during cognitive tasks have been reported in major depressive disorder (MDD). However, prefrontal asymmetry during cognitive tasks and its relation to suicide ideations have been less frequently examined in patients with MDD. This study investigated prefrontal asymmetry and its moderating effect on the relationship between depression severity and suicidal ideation in MDD patients during cognitive tasks. Forty-two patients with MDD and 64 healthy controls (HCs) were assessed for changes in oxygenated and deoxygenated hemoglobin $(\mathrm{Hb})$ in the prefrontal cortex using functional near-infrared spectroscopy (fNIRS) during the verbal fluency task (VFT), Stroop task, and two-back task. Depression, anxiety, and suicide ideation were measured through self-report questionnaires. Relatively smaller left oxy-Hb changes during VFT, but not during the Stroop or two-back tasks, were found in MDD patients compared with HCs. Furthermore, prefrontal asymmetry during VFT moderated the effect of depression severity on suicide ideation, and was significantly and positively correlated with suicide ideation in patients with MDD. Specifically, relatively greater left oxy- $\mathrm{Hb}$ changes were associated with greater suicide ideation. These findings suggest fNIRS-measured prefrontal asymmetry as a potential biomarker for MDD and for the assessment of suicidal risk in patients with MDD.
\end{abstract}

Keywords: spectroscopy; near-infrared; prefrontal cortex; cognition; depression; suicide

\section{Introduction}

\subsection{Background}

Depression is a leading cause of disability worldwide, with over 300 million individuals suffering from the disorder [1]. At its worst, depression can be life-threatening; around $50 \%$ of suicide attempters are diagnosed with depression [2]. Over the past few decades, a large body of research has investigated the biomarkers of depression to facilitate diagnosis and optimize treatment decisions. One emerging diagnostic tool for depression is functional near-infrared spectroscopy (fNIRS), an optical neuroimaging technology that uses near-infrared light to track changes in the concentration of oxygenated and deoxygenated hemoglobin $(\mathrm{Hb})$ [3]. The use and development of fNIRS has increased tremendously in neuroscience and psychiatric research, and is expected to become a robust and reliable clinical tool (for review, see the work of [4]). In particular, the technique of fNIRS is suitable for measuring oxygenation changes in prefrontal areas associated with cognitive tasks [5-7]. 
With regard to depression, reduced $\mathrm{Hb}$ changes during cognitive activation have been suggested as potential biomarkers [8]. Previous studies found that patients with major depressive disorder (MDD) show reduced prefrontal oxygenation during cognitive tasks, such as verbal fluency [8-10], and working memory tasks [11,12]. However, there are mixed evidence regarding hemispheric asymmetry. Some studies found relatively reduced $\mathrm{Hb}$ in the left prefrontal regions $[13,14]$, whereas others did not report hemispheric differences during cognitive tasks in depressed individuals [15-17]. Nonetheless, previous studies suggest a significant association between prefrontal asymmetry and cognitive function in depression. For instance, a recent study discovered that the trait approach and avoidance motivation were associated with activation of the left and right prefrontal cortex, respectively, during executive functioning [18]. Likewise, depressed individuals who are characterized by avoidance motivation would show reduced left frontal activation during cognitive tasks. Other studies also suggested that deficits in executive functions in depression, such as the initiation and strategic use of information, may be because of the failure of left prefrontal cortex activation $[19,20]$. Moreover, relatively reduced left prefrontal activation (i.e., more electroencephalogram (EEG) alpha activity) during rest has been reported to be a trait marker of depression [21].

Importantly, comorbidity and different methodologies should be considered when studying prefrontal asymmetry. Depression is often associated with anxiety, which may show a pattern opposite to that of frontal asymmetry found in depression (i.e., relatively greater left frontal activity) [22,23]. In addition, frontal asymmetry may differ according to the presence of suicide ideation [24]. Methods to assess prefrontal asymmetry (e.g., hemisphere as a two-level factor in statistical analysis versus direct measurement using lateral index) and the running time of the applied cognitive test may affect the results as well. For example, in a verbal fluency task (VFT), a shorter duration trial (e.g., $30 \mathrm{~s}$ versus $60 \mathrm{~s})$ may be more sensitive to the left frontal function, as it requires more frequent shifting among phonemes, and thus more initiation [25].

Meanwhile, suicide ideation is one of the symptoms of depression that is associated with cognitive rigidity and executive functioning deficits related to impairments of the frontal lobe [26-28]. Among depressed individuals, the pattern of prefrontal asymmetry was associated differently with suicide ideation. Suicide ideation was related to relatively increased activity in the left frontal regions of the brain, and patients with major depressive disorder (MDD) with suicide ideation showed greater left activity than patients without suicide ideation [24,29]. An imaging study also revealed a relative hypometabolism of the right dorsolateral cortex and hypermetabolism of the left ventromedial cortex in patients with MDD and a history of suicide attempts [30]. Moreover, smaller hemodynamic changes were found in the right prefrontal cortex in patients with MDD with suicide ideation compared with those without [31]. While these findings suggest that prefrontal asymmetry contributes to suicidality, the role of prefrontal asymmetry in linking depression to suicide ideation is expected to help identify depressed individuals with suicide risk. Also, the results of the previous studies need to be replicated owing to the limited number of studies and conflicting reports from others [32,33].

\subsection{Aim of this Study}

The present study aimed to investigate prefrontal asymmetry during cognitive tasks in patients with MDD, using fNIRS. We hypothesized that patients with MDD would show relatively reduced $\mathrm{Hb}$ in the left prefrontal cortex compared with healthy controls (HCs). We also hypothesized that relatively greater $\mathrm{Hb}$ levels in the left prefrontal cortex would be associated with suicide ideation and moderate the effect of depression severity on suicide ideation among patients with MDD. 


\section{Materials and Methods}

\subsection{Participants}

A total of 125 participants (53 Patients with MDD and 72 HCs) between the ages of 19 and 65 from Ilsan Paik Hospital and the local community were included in this study. Participants with sensory impairments, epilepsy, and brain injury were excluded. In addition, we excluded patients with MDD with a history of psychosis symptoms and HCs with present or prior diagnosis of any type of mental disorder. MDD was diagnosed according to the Diagnostic and Statistical Manual of Mental Disorders, Fifth Edition [34], by a board-certified psychiatrist. Patients with MDD and HCs were matched with respect to age and sex.

One participant dropped out during the experiment, and eight participants were excluded from analysis owing to missing data. In addition, data exceeding \pm 3 SD from the mean asymmetry index of each task ( 2 for Stroop task, 3 for VFT, and 5 for two-back task) were considered outliers and were excluded from analysis. Thus, the final sample consisted of 106 participants, which included 42 patients with MDD and 64 HCs.

All procedures were approved by the Institutional Review Board of Inje University Ilsan Paik Hospital (2017-10-013). Informed consent was obtained from all participants prior to study enrollment.

\subsection{Psychological Measures}

Depression severity was assessed using the Korean version of the Beck's depression inventory-II (BDI-II), which is composed of 21 items rated on a four-point scale. This self-reported inventory showed a high Cronbach's alpha $(\alpha=0.85)$ and test-retest reliability $(r=0.75)$ [35]. The internal consistency of the current sample was $\alpha=0.95$. Anxiety severity was measured using the Korean version of the State-trait anxiety inventory, a self-reported inventory consisting of 20 items that assess state anxiety and 20 items that assess trait anxiety. The state anxiety section (SAI) was used for the current study. The internal consistencies of the Korean version of SAI and the current sample were $\alpha=0.91$ [36] and $\alpha=0.96$, respectively.

Finally, suicide ideation was assessed using the suicide item (item 3) of Hamilton's depression rating scale (HAM-D) (1960) [31,37,38]. Item 3 assesses the level of suicide ideation and is rated on a $0-4$ scale $(0=$ absent, 1 = feels life is not worth living, 2 = wishes to be dead or any thought of possible death to self, 3 = suicidal ideas or gesture, 4 = suicide attempts).

\subsection{Cognitive Tasks}

$\mathrm{Hb}$ changes were measured during three different cognitive tasks: VFT, Stroop task, and two-back task. These tasks were chosen as they measure executive functioning, which is a kind of cognitive deficit associated mostly with depression [39-41] and frontal asymmetry [42].

The changes in $\mathrm{Hb}$ were measured while the participants performed all three cognitive tasks. The participants were seated in a comfortable chair and told to relax and avoid movements in order to minimize artifacts. They went through a practice session of the cognitive tasks (60-120 s per task) before the formal experiment. Each task was composed of three blocks with a $30 \mathrm{~s}$ resting period between the blocks (Figure 1). The tasks were designed using E-prime 2.0. Participants received a compensation of $\$ 50$ if they properly completed the whole experiment. 


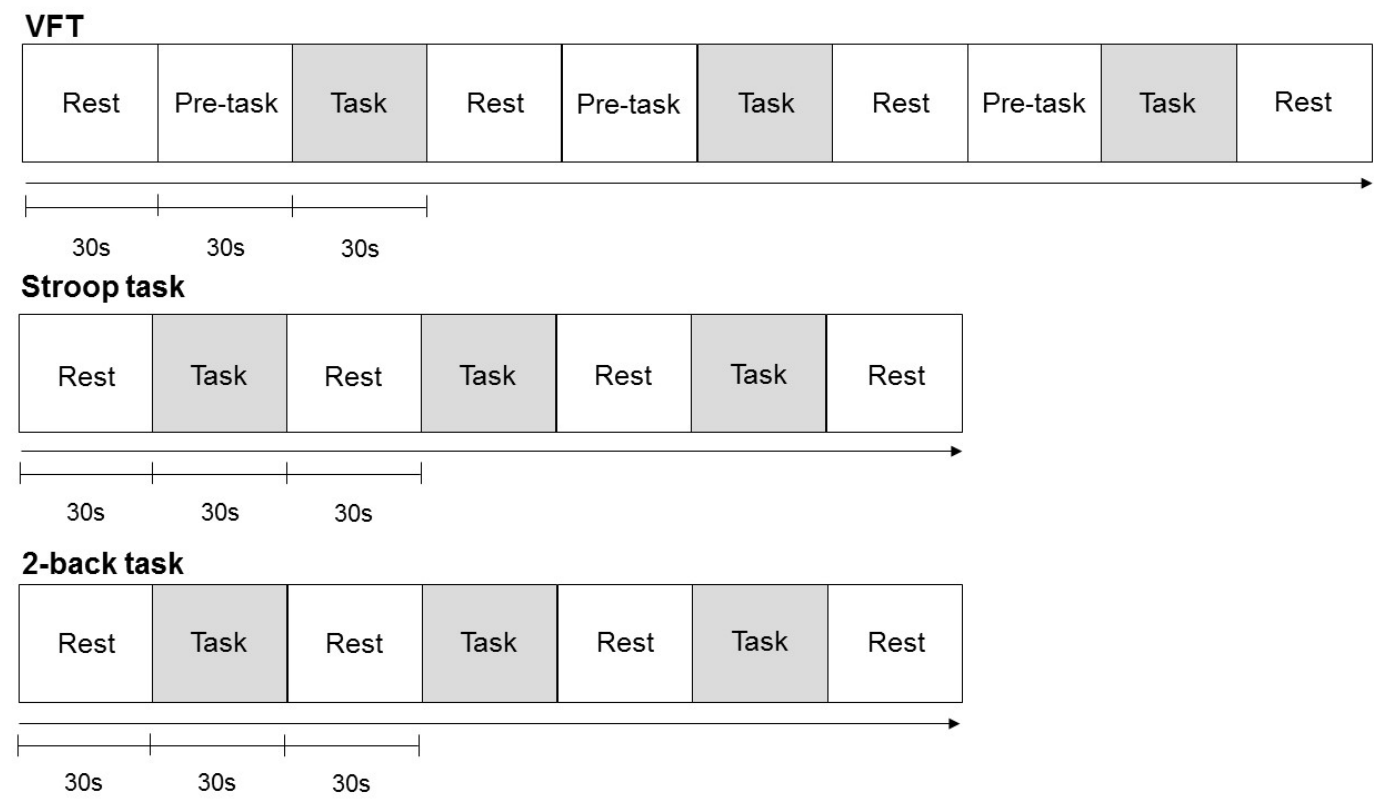

Figure 1. Cognitive task protocol used for the near-infrared spectroscopy (NIRSIT) system. Note: VFT $=$ verbal fluency task.

\subsubsection{Verbal Fluency Task}

VFT involves generating as many words that begin with a specified phoneme as possible within a certain time frame [43]. Each block of the VFT consisted of two parts: a $30 \mathrm{~s}$ pre-task baseline and the 30 s VFT task. During the pre-task, the participants were instructed to consecutively repeat the Korean consonants "g", " $n$ ", "d", and " $r$ " out loud. During the VFT task period, the participants were instructed to produce as many words beginning with a designated consonant as possible, while avoiding homonyms and proper nouns. The designated consonant was randomly selected from the eight consonants "g", "n", "d", "r", "m", "b", "s", and "h". All responses were recorded.

\subsubsection{Korean Stroop Task}

A Korean version of the color-word Stroop task was administered to measure selective attention [44]. For each trial, two rows of words were displayed on a black screen. On the top row, a word appeared in one of the seven different colors, that is, "red", "blue", "yellow", "gray", "orange", "pink", or "green", different from the one indicated by the word's meaning (e.g., the word "red" was written in ink color green). On the bottom row, two different words for colors were written in white on the left and right side. The ink color and the word stimulus were presented randomly among the seven colors. The participants had to decide which of the two colors at the bottom corresponded to the ink color of the word displayed on the top row by pressing the left and right arrow buttons on the keyboard (e.g., the left arrow was pressed to choose the word on the left) as quickly and accurately as possible. The next trial only started after the participants responded to this. The number of trials presented per block depended on the subject's response speed.

\subsubsection{N-Back Task (Two-Back Task)}

A two-back task with number stimuli was used to assess working memory [45]. During this task, the participants viewed numbers between 1 and 5 that successively appeared on the screen one at a time. Each number appeared on the screen for $1 \mathrm{~s}$, with a $0.5 \mathrm{~s}$ interval between the trials. The numbers appeared in black against a white background, in the middle of the screen. The participants had to identify the number (i.e., the target) that corresponded to the number presented on the screen 2 trials earlier by pressing the left button of the mouse. The total number of trials per block was 20 , and the target stimuli appeared in $40 \%$ of the trials. 


\section{4. fNIRS}

A high density NIRS device (NIRSIT; OBELAB, Seoul, Korea) measured the relative changes in oxy- $\mathrm{Hb}$ and deoxy- $\mathrm{Hb}$. The sensor array was comprised of 24 dual-wavelength laser diodes $(780 / 850 \mathrm{~nm})$ and 32 photo detectors separated by a $1.5 \mathrm{~cm}$ unit distance [46]. A $3 \mathrm{~cm}$ distance separated the laser and detector pairs at 48 sensing areas, and the optical signal variation of each channel was sampled at $8.138 \mathrm{~Hz}$. The threshold signal-to-noise ratio was $30 \mathrm{~dB}$, and it was used to qualify the noise of the detected channels after band-pass filtering from 0.005 to $0.1 \mathrm{~Hz}$ and remove the slow drift of physiological noise and environmental noise. Relative hemodynamic changes in each channel during each trial of each task were extracted using the Modified Beer Lambert Law (MBLL) [47]. The baseline value of relative change was defined as the averaged value from -5 to $0 \mathrm{~s}$ before the start of each task period. The multiple trial results are block averaged individually, and grand averaging was applied to extract the representative mapping result from each group.

Prefrontal asymmetry was defined as a lateral index, which measured the difference in $\mathrm{Hb}$ concentration changes between the left and right hemispheres divided by their sum: (left $\mathrm{Hb}$ - right $\mathrm{Hb}) /($ left $\mathrm{Hb}+$ right $\mathrm{Hb}$ ). A positive value indicates greater $\mathrm{Hb}$ in the left hemisphere, whereas a negative value indicates greater $\mathrm{Hb}$ in the right hemisphere.

\subsection{Statistical Analyses}

Behavioral data and the asymmetry index were compared between the groups using one-way analysis of covariance (ANCOVA). In addition to education, which significantly differed between the groups, age, sex, SAI, and item 3 of HAM-D3 were included as covariates because of their potential effects on hemodynamic responses and frontal asymmetry [23,24,48,49]. Also, correlation analyses were performed to examine the relationships of the asymmetry index of the three tasks with psychological and behavioral measures. Bootstrap resampling $(n=5000)$ was used to correct multiple correlations [50]. Finally, the moderating role of prefrontal asymmetry on the link between depression and suicide ideation was assessed using SPSS macro PROCESS v3.1.

The significance level was set at $p<0.05$ (two-tailed). Statistical analyses were performed using SPSS 21 (SPSS, INC., Chicago, IL, USA).

\section{Results}

The analysis of deoxy-Hb was not significant; therefore, we focused on the oxy- $\mathrm{Hb}$ results. $\mathrm{Oxy}-\mathrm{Hb}$ concentration has been suggested to better reflect cortical activity and be more strongly correlated with blood oxygenation level dependent (BOLD) signals measured by fMRI [51,52].

\subsection{Demographics and Other Characteristics}

Demographic information and scores of psychological scales are presented in Table 1. Patients with MDD had significantly fewer years of education $(p=0.020)$ and higher Beck's depression inventory-II (BDI-II) $(p<0.001)$, State anxiety inventory (SAI) $(p<0.001)$, and Hamilton's depression rating scale (HAM-D) $(p<0.001)$ scores compared with HCs. Overall oxy-Hb changes during the cognitive tasks are presented in Figure 2. 
Table 1. Demographic characteristics of participants.

\begin{tabular}{cccc}
\hline & $\begin{array}{c}\text { Patients with MDD } \\
(\boldsymbol{n}=\mathbf{4 2})\end{array}$ & $\begin{array}{c}\text { HCs } \\
(\boldsymbol{n}=\mathbf{6 4})\end{array}$ & $\boldsymbol{p}$ \\
\hline Age & $37.62 \pm 14.36$ & $33.42 \pm 12.57$ & 0.115 \\
Sex & & & 0.685 \\
Male & 17 & 24 & \\
Female & 34 & 41 & \\
Education (years) & $11.62 \pm 2.71$ & $12.98 \pm 3.03$ & 0.020 \\
BDI-II & $22.21 \pm 13.74$ & $8.51 \pm 7.02$ & $<0.001$ \\
SAI & $49.95 \pm 13.34$ & $34.11 \pm 8.07$ & $<0.001$ \\
HAM-D & $20.31 \pm 11.14$ & $4.84 \pm 5.06$ & $<0.001$ \\
\hline
\end{tabular}

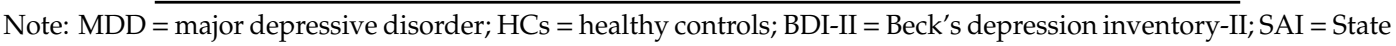
anxiety inventory; HAM-D = Hamilton depression rating scale.

(a) VFT

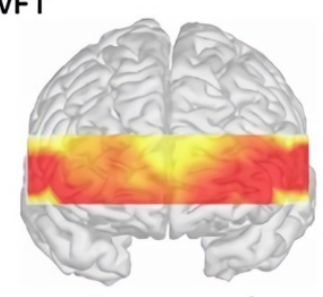

$\mathbf{R}$

$\mathbf{L}$

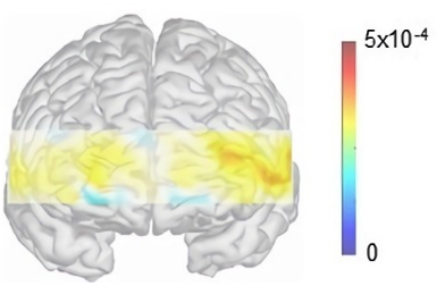

(b) Stroop task
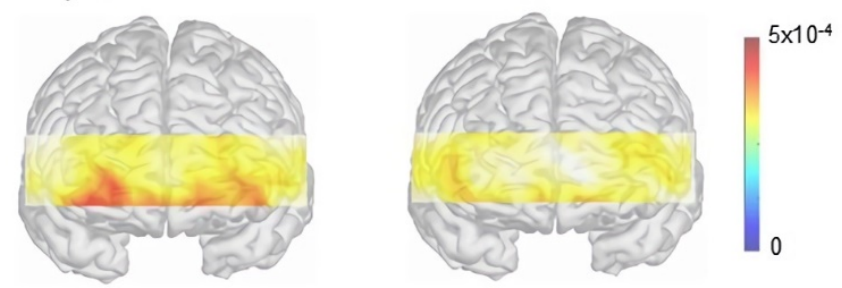

(c) Two-back task

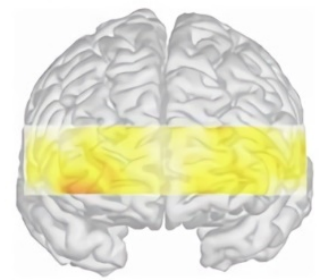

$\mathrm{HC}$



MDD

Figure 2. Oxygenated hemoglobin changes in patients with MDD and HCs during (a) Stroop task; (b) VFT; and (c) two-back task. Note: MDD = major depressive disorder, HCs = healthy controls; $\mathrm{VFT}=$ verbal fluency task.

\subsection{Behavioral Analysis}

There were no significant group differences in the average number of words generated in VFT or the accuracy and reaction time for the Stroop task and two-back task (Table 2). 
Table 2. Behavioral analyses of patients with MDD and HCs with age, sex, education, item 3 of HAM-D, and SAI as covariates.

\begin{tabular}{ccccc}
\hline & Patients with MDD & HC & $\boldsymbol{F}$ & $p$ \\
\hline VFT & & & & \\
Word count & $20.56 \pm 8.50$ & $24.67 \pm 6.99$ & 0.149 & 0.700 \\
Stroop task & & & & \\
$\quad$ Accuracy & $0.89 \pm 0.11$ & $0.93 \pm 0.06$ & 0.287 & 0.594 \\
$\quad$ RT (ms) & $1815.82 \pm 1055.01$ & $1345.27 \pm 690.72$ & 1.377 & 0.243 \\
Two-back task & & & & \\
Accuracy & $0.78 \pm 0.10$ & $0.84 \pm 0.10$ & 0.364 & 0.548 \\
RT (ms) & $585.44 \pm 89.79$ & $593.42 \pm 90.66$ & 1.105 & 0.322 \\
\hline
\end{tabular}

Note: MDD = major depressive disorder; HCs = healthy controls; VFT = verbal fluency task; HAM-D = Hamilton depression rating scale; $\mathrm{SAI}=$ State anxiety inventory; $\mathrm{RT}$ = reaction time; Bold text in the first column indicates the type of cognitive task.

\subsection{Prefrontal Asymmetry}

\subsubsection{Group Differences in Prefrontal Asymmetry}

For VFT, one-way ANCOVA revealed a significant main effect of the group on prefrontal asymmetry for oxy- $\mathrm{Hb}(\mathrm{F}(1,97)=9.12, p=0.003)$. The mean asymmetry index for oxy-Hb was significantly lower in patients with $\mathrm{MDD}(\mathrm{M}=-0.13, \mathrm{SD}=0.46)$ compared with the $\mathrm{HCs}(\mathrm{M}=0.17, \mathrm{SD}=0.80)$. In other words, mean oxy- $\mathrm{Hb}$ concentration changes were relatively lower in the left hemisphere compared with the right hemisphere in patients with MDD, whereas the opposite pattern was found in HC (Figure 3). In order to examine the effects of age and sex on asymmetry, we performed an additional ANCOVA modeling with age and sex, and did not find a significant effect of age $(F(1,102)=0.667$, $p=0.192)$ or $\operatorname{sex}(\mathrm{F}(1,102)=0.119, p=0.581)$ on the group differences in oxy-Hb changes during VFT. No significant results were found for either the Stroop or two-back tasks.
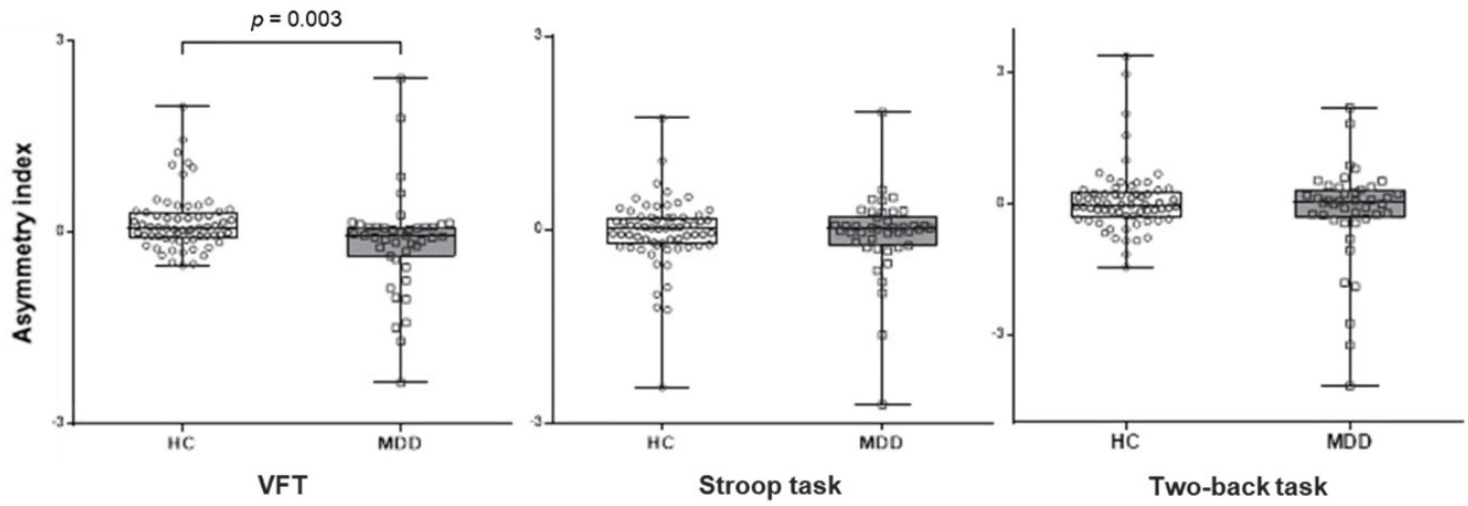

Figure 3. Mean asymmetry index during VFT, Stroop, and two-back tasks in patients with MDD and $\mathrm{HCs}$. Asymmetry index was measured using the lateral index: (left oxy-Hb - right oxy-Hb)/(left oxy $\mathrm{Hb}+$ right oxy-Hb). Note: $\mathrm{MDD}=$ major depressive disorder; $\mathrm{HCs}=$ healthy controls; VFT = verbal fluency task.

For deoxy-Hb data, there were no significant group differences in the mean asymmetry index for VFT $(F(1,97)=4.215, p=0.090)$, Stroop $(F(1,97)=3.470, p=0.066)$, and two-back tasks $(\mathrm{F}(1$, 97) $=9.12, p=0.060$ ).

\subsubsection{Correlation between Asymmetry Index and Psychological Measures}

For patients with MDD, there was a significant positive correlation between the asymmetry index for VFT and the suicide item (item 3$)$ of HAM-D ( $r=0.313, p=0.046)$. For HC, we found a significant negative correlation between the asymmetry index for the Stroop task and SAI $(r=-0.337, p=0.006)$. 
There were no other significant correlations among BDI-II, SAI, item 3 of HAM-D, and asymmetry index of the three tasks. For all participants (patients with MDD + HC), there were no significant correlations.

\subsubsection{Correlation between Asymmetry Index and Behavioral Measures}

There was a significant positive correlation between the asymmetry index and response accuracy for the two-back task $(r=0.282, p=0.007)$ in MDD patients. However, there were no significant correlations between asymmetry index and behavioral measures for the VFT and Stroop task.

\subsection{Moderation Effect}

For VFT, the moderation model suggested a significant interaction effect of prefrontal asymmetry for oxy-Hb and depression severity on suicide ideation (Table 3, Figure 4). The variance increase due to the interaction effect was $\mathrm{R}^{2}=0.11$. The $95 \%$ confidence interval $(\mathrm{CI})$ did not cross the value zero, CI $[0.009,0.039]$. Furthermore, the conditional indirect effect revealed that the relationship between depression severity and suicide ideation was moderated by prefrontal asymmetry at all levels (i.e., high, average, low) of the moderator. However, the strength of moderation was stronger at one SD above (i.e., greater left concentration), compared with one SD below (i.e., reduced left concentration) the mean asymmetry index. No significant interaction effects were found for the Stroop or two-back tasks. In addition, there were no significant interaction effects between depression severity and the mean asymmetry index for deoxy-Hb in VFT $(p=0.363)$, Stroop $(p=0.112)$, and two-back tasks $(p=0.163)$.

Table 3. Moderation analysis of the relationship between depression severity and suicide ideation by prefrontal asymmetry during VFT among patients with MDD.

\begin{tabular}{|c|c|c|c|c|c|c|c|c|c|}
\hline & $B$ & se & $t$ & $p$ & $L L C I$ & $U L C I$ & $R^{2}$ & $\Delta R^{2}$ & $F$ \\
\hline Constant & -1.036 & 1.071 & -0.969 & 0.338 & -3.202 & 1.127 & & & \\
\hline BDI & 0.027 & 0.019 & 1.465 & 0.151 & -0.010 & 0.065 & & & \\
\hline VFT asymmetry & -0.134 & 0.193 & -0.696 & 0.491 & -0.523 & 0.256 & 0.442 & & $6.332 * * *$ \\
\hline Sex & 0.145 & 0.497 & 0.291 & 0.773 & -0.860 & 1.149 & & & \\
\hline SAI & 0.028 & 0.016 & 1.773 & 0.084 & -0.004 & 0.060 & & & \\
\hline $\begin{array}{l}\text { BDI *VFT } \\
\text { asymmetry }\end{array}$ & 0.027 & 0.012 & 2.276 & 0.028 & 0.0031 & 0.053 & & 0.072 & $5.176 *$ \\
\hline \multirow{4}{*}{$\begin{array}{l}\text { Conditional } \\
\text { Indirect } \\
\text { effect }\end{array}$} & & & \multicolumn{2}{|c|}{ VFT asymmetry } & Effect & Boot $L L C I$ & \multicolumn{3}{|c|}{ Boot ULCI } \\
\hline & \multirow{2}{*}{\multicolumn{2}{|c|}{$\begin{array}{c}\text { Mean - } 1 S D \\
\text { Mean }\end{array}$}} & \multicolumn{2}{|c|}{-0.931} & 0.023 & 0.004 & \multicolumn{3}{|c|}{0.042} \\
\hline & & & \multirow{2}{*}{\multicolumn{2}{|c|}{$\begin{array}{c}-0.130 \\
0.670\end{array}$}} & 0.042 & 0.026 & \multicolumn{3}{|c|}{0.057} \\
\hline & \multicolumn{2}{|c|}{ Mean + $1 S D$} & & & 0.061 & 0.040 & & 0.081 & \\
\hline
\end{tabular}

Note: VFT = verbal fluency task; MDD = major depressive disorder; LLCI: lower levels for confidence interval; ULCI: upper levels for confidence interval, ${ }^{*} p<0.05,{ }^{* * *} p<0.001$.
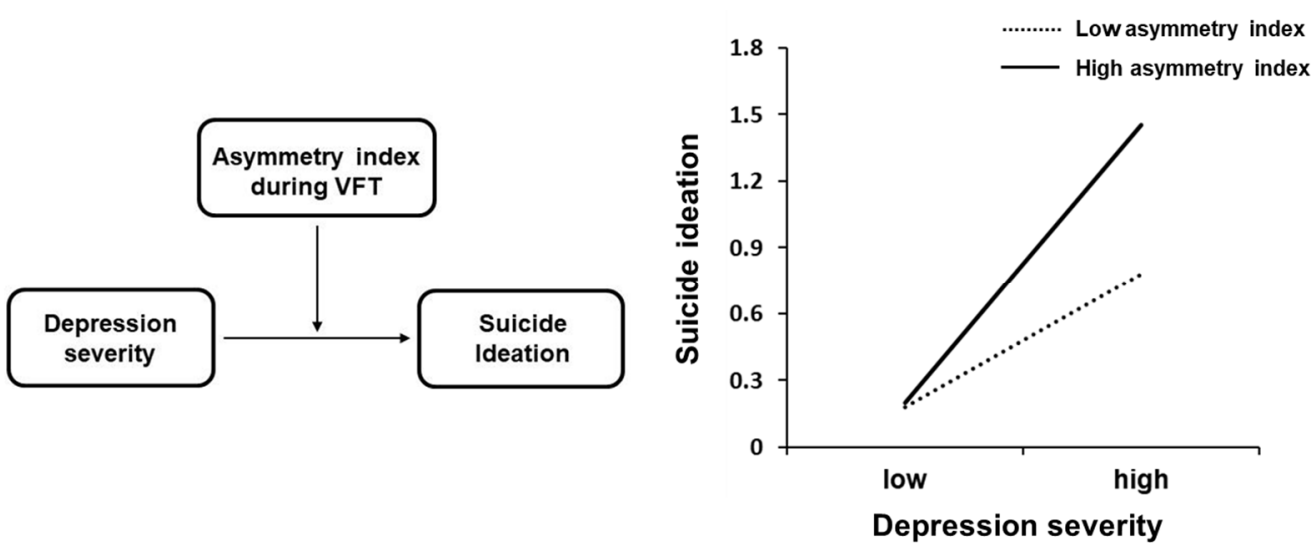

Figure 4. Moderating effect of prefrontal asymmetry index on the relationship between depression and suicide ideation in patients with major depressive disorder (MDD). Note: VFT = verbal fluency task. 


\section{Discussion}

This study investigated prefrontal hemispheric asymmetry in patients with MDD by measuring oxy-Hb concentration changes using fNIRS during cognitive tasks and its moderating role in the relationship between depression severity and suicide ideation. Our results indicated that patients with MDD have relatively reduced left prefrontal oxy-Hb changes during VFT compared with HCs. Furthermore, prefrontal asymmetry moderated the relationship between depression severity and suicide ideation. Specifically, the effect of depression severity on suicide ideation was stronger when the left prefrontal activation was higher.

The findings from the present study suggest that relatively reduced left prefrontal activity during VFT distinguishes patients with MDD from HCs. These results are consistent with that of previous studies that found hypoactivity to be most prominent in the left frontal lobe in depressed individuals during VFT. For instance, Ohta et al. demonstrated that attenuated prefrontal activity in patients with MDD was most pronounced in the left medial inferior lobe during VFT. Another NIRS study indicated reduced activity of the left frontal cortex in patients with mandatory depressive symptoms (depressed mood or loss of interest or pleasure), but not in remitted patients with residual symptoms during VFT [14]. Moreover, positron emission tomography (PET) [53,54] and EEG studies [21,55] have shown reduced activity in the left frontal cortex in patients with MDD.

In contrast, other studies found bilateral hypoactivity without any difference in the activation levels between the hemispheres $[16,17,56]$ and even a similar level of activation with HCs in both hemispheres [57] in patients with MDD. The different results may be the result of several methodological differences. Most of these studies did not take suicide ideation or anxiety symptoms into account, whereas these were controlled as covariates in the present study. Furthermore, unlike most studies that statistically investigated the effect of hemisphere using repeated measures ANOVA, this study computed the asymmetry index to observe the relative difference between hemispheres. Lateral asymmetry index has several advantages such as high internal consistency [58] and the avoidance of individual differences like skull thickness [59,60]. Lastly, the duration of each VFT trial was shorter in the current study (30 s) compared with previous studies (mostly $60 \mathrm{~s}$ ). A shorter time constraint may indicate greater initiation, as it requires more shifts from one phoneme to another, which is suggested to be associated with left frontal lobe activity [25,61].

In addition, there was no significant correlation between total word count during VFT and the asymmetry index. This indicates that VFT performance is unrelated to the oxygenation changes, as also reported by previous studies [62-64]. Thus, it is unlikely that the group differences in oxy-Hb changes found in the present study contributed to the performance of VFT per se.

The second major finding of this study was the moderating effect of prefrontal asymmetry on the link between depression severity and suicide ideation. We found that the effect of depression on suicide ideation was stronger when there was relatively greater left prefrontal asymmetry. The correlational analysis also revealed that a relatively higher left oxy- $\mathrm{Hb}$ concentration was associated with greater suicide ideation, further supporting the moderation effect. These results are in line with those of previous studies that found relatively greater left frontal activity in individuals with suicide ideation $[24,29,31]$. The moderation effect may be a result of the involvement of relatively greater left or reduced right prefrontal activity with behaviors like impulsivity, a characteristic that can distinguish between suicidal and non-suicidal patients with MDD [65-67]. Gable et al. [68] also proposed that the right frontal cortex is associated with the regulation and supervision of the motivational systems; thus, its hypoactivity indicates deficits of inhibitory control. Therefore, relatively greater left prefrontal activation compared with right may reflect reduced cognitive control or greater impulsivity, which may lead to greater suicidal ideation among patients with MDD. Nonetheless, it is also plausible that the effect of prefrontal asymmetry reflects the processing of VFT, unrelated to aspects of cognitive control. As there is a scarcity of literature on frontal asymmetry and suicide ideation, future studies are necessary to examine the underlying mechanisms of the relationship between frontal asymmetry and suicide ideation among patients with MDD. 
Lastly, all significant findings in our study were specific to VFT, and insignificant results were only obtained in the Stroop and two-back tasks. This may indicate that the relatively attenuated left prefrontal activation in patients with MDD is associated with distinct characteristics of VFT. In fact, VFT has been shown to be largely associated with left prefrontal regions $[69,70]$, whereas relatively few studies have examined hemispheric differences in the Stroop and two-back tasks [71-73], leading to ambiguous results. Moreover, several researchers [25,74] have suggested that VFT may be particularly sensitive to depression owing to the overlap between the cognitive demands of VFT and the cognitive deficits associated with depression, such as initiation, sustained attention, retrieval, and persistence.

There are several limitations to this study. First, extracerebral hemodynamics caused by physiological changes were not separated from measured signals, as the fNIRS device used in this study does not have a short distance channel under $1 \mathrm{~cm}$ [75]. Yet, previous studies like that of Takizawa et al. (2014) showed that the hemodynamics parameter derived from averaging during each task period without short channel separation can be used for assessing patients' differential depressive state. Second, although we attempted to statistically control anxiety severity, some participants had anxiety symptoms. Various anxiety domains, such as anxious apprehension and anxious arousal, have been suggested to show different patterns of frontal asymmetry [22,23]. Third, most of the patients were under medication. The results of studies into the effects of antidepressants on NIRS signaling have been mixed, with some studies reporting no or minor effects [76-78] and others reporting major effects of certain drugs on prefrontal NIRS signals [79-81]. In the present study, we found no significant relationship between medication status and oxy- $\mathrm{Hb}$ signals.

\section{Conclusions}

The present study demonstrated that patients with MDD exhibit relatively reduced left prefrontal oxy-Hb changes during VFT compared with HCs. Also, there was a moderating effect of prefrontal asymmetry on the link between depression severity and suicide ideation. These results suggest that prefrontal asymmetry, measured by fNIRS, is a potential biomarker for MDD diagnosis and for identifying suicidal risk in patients with MDD. Future studies could assess how factors like motivation and cognitive control relate to prefrontal asymmetry during cognitive tasks in depression.

Author Contributions: Conceptualization, S.-H.L.; formal analysis, J.C., S.Y.B., J.-Y.K., and J.Y.B.; methodology, S.-H.L. and S.Y.B; writing-original draft preparation, S.Y.B. and J.C.; writing-review and editing, S.-H.L.; supervision, S.-H.L.; visualization, J.-Y.K., J.C., and S.Y.B.; investigation, Y.P., S.Y.B., Y.K., and M.J.; funding acquisition, S.-H.L.

Funding: This work was supported by the 2017 creative research program of Inje University, and a grant from the Korea Science and Engineering Foundation (KOSEF), funded by the Korean government (NRF-2018R1A2A2A05018505).

Conflicts of Interest: The authors declare no conflict of interest. The funders had no role in the design of the study; in the collection, analyses, or interpretation of data; in the writing of the manuscript, or in the decision to publish the results.

$\begin{array}{ll}\text { Abbreviations } \\ \text { MDD } & \text { Major depressive disorder } \\ \mathrm{HC} & \text { Healthy control } \\ \mathrm{Hb} & \text { Hemoglobin } \\ \text { fNIRS } & \text { Functional near-infrared spectroscopy } \\ \text { VFT } & \text { Verbal fluency task } \\ \text { BDI-II } & \text { Beck's depression inventory-II } \\ \text { SAI } & \text { State anxiety inventory } \\ \text { HAM-D } & \text { Hamilton's depression rating scale } \\ \text { EEG } & \text { Electroencephalogram }\end{array}$




\section{References}

1. Available online: https://www.who.int/news-room/fact-sheets/detail/depression (accessed on 14 November 2019).

2. Reddy, M. Depression: The disorder and the burden. Indian J. Psychol. Med. 2010, 32, 1. [CrossRef]

3. Di Domenico, S.I.; Rodrigo, A.H.; Dong, M.; Fournier, M.A.; Ayaz, H.; Ryan, R.M.; Ruocco, A.C. Functional Near-Infrared Spectroscopy: Proof of Concept for Its Application in Social Neuroscience. In Neuroergonomics; Elsevier: Amsterdam, The Netherlands, 2019; pp. 169-173.

4. Scholkmann, F.; Kleiser, S.; Metz, A.J.; Zimmermann, R.; Pavia, J.M.; Wolf, U.; Wolf, M. A review on continuous wave functional near-infrared spectroscopy and imaging instrumentation and methodology. Neuroimage 2014, 85, 6-27. [CrossRef] [PubMed]

5. Herrmann, M.; Ehlis, A.-C.; Fallgatter, A. Frontal activation during a verbal-fluency task as measured by near-infrared spectroscopy. Brain Res. Bull. 2003, 61, 51-56. [CrossRef]

6. Ehlis, A.-C.; Herrmann, M.; Wagener, A.; Fallgatter, A. Multi-channel near-infrared spectroscopy detects specific inferior-frontal activation during incongruent Stroop trials. Biol. Psychol. 2005, 69, 315-331. [CrossRef] [PubMed]

7. Takeda, T.; Kawakami, Y.; Konno, M.; Matsuda, Y.; Nishino, M.; Suzuki, Y.; Kawano, Y.; Nakajima, K.; Ozawa, T.; Kondo, Y. PFC blood oxygenation changes in four different cognitive tasks. In Oxygen Transport to Tissue; Springer: Berlin, Germany, 2017; pp. 199-204.

8. Suto, T.; Fukuda, M.; Ito, M.; Uehara, T.; Mikuni, M. Multichannel near-infrared spectroscopy in depression and schizophrenia: Cognitive brain activation study. Biol. Psychiatry 2004, 55, 501-511. [CrossRef]

9. Matsuo, K.; Onodera, Y.; Hamamoto, T.; Muraki, K.; Kato, N.; Kato, T. Hypofrontality and microvascular dysregulation in remitted late-onset depression assessed by functional near-infrared spectroscopy. Neuroimage 2005, 26, 234-242. [CrossRef]

10. Tomioka, H.; Yamagata, B.; Kawasaki, S.; Pu, S.; Iwanami, A.; Hirano, J.; Nakagome, K.; Mimura, M. A longitudinal functional neuroimaging study in medication-naive depression after antidepressant treatment. PLoS ONE 2015, 10, e0120828. [CrossRef]

11. Schecklmann, M.; Dresler, T.; Beck, S.; Jay, J.T.; Febres, R.; Haeusler, J.; Jarczok, T.A.; Reif, A.; Plichta, M.M.; Ehlis, A.-C. Reduced prefrontal oxygenation during object and spatial visual working memory in unpolar and bipolar depression. Psychiatry Res. Neuroimaging 2011, 194, 378-384. [CrossRef]

12. Pu, S.; Yamada, T.; Yokoyama, K.; Matsumura, H.; Kobayashi, H.; Sasaki, N.; Mitani, H.; Adachi, A.; Kaneko, K.; Nakagome, K. A multi-channel near-infrared spectroscopy study of prefrontal cortex activation during working memory task in major depressive disorder. Neurosci. Res. 2011, 70, 91-97. [CrossRef]

13. Okada, G.; Okamoto, Y.; Yamashita, H.; Ueda, K.; Takami, H.; Yamawaki, S. Attenuated prefrontal activation during a verbal fluency task in remitted major depression. Psychiatry Clin. Neurosci. 2009, 63, 423-425. [CrossRef]

14. Akiyama, T.; Koeda, M.; Okubo, Y.; Kimura, M. Hypofunction of left dorsolateral prefrontal cortex in depression during verbal fluency task: A multi-channel near-infrared spectroscopy study. J. Affect. Disord. 2018, 231, 83-90. [CrossRef] [PubMed]

15. Ohta, H.; Yamagata, B.; Tomioka, H.; Takahashi, T.; Yano, M.; Nakagome, K.; Mimura, M. Hypofrontality in panic disorder and major depressive disorder assessed by multi-channel near-infrared spectroscopy. Depress. Anxiety 2008, 25, 1053-1059. [CrossRef] [PubMed]

16. Herrmann, M.; Ehlis, A.-C.; Fallgatter, A. Bilaterally reduced frontal activation during a verbal fluency task in depressed patients as measured by near-infrared spectroscopy. J. Neuropsychiatry Clin. Neurosci. 2004, 16, 170-175. [CrossRef] [PubMed]

17. Ma, X.-Y.; Wang, Y.-J.; Xu, B.; Feng, K.; Sun, G.-X.; Zhang, X.-Q.; Liu, X.-M.; Shen, C.-Y.; Ren, X.-J.; Sun, J.-J. Near-infrared spectroscopy reveals abnormal hemodynamics in the left dorsolateral prefrontal cortex of menopausal depression patients. Dis. Markers 2017, 2017, 1695930. [CrossRef] [PubMed]

18. Spielberg, J.M.; Miller, G.A.; Engels, A.S.; Herrington, J.D.; Sutton, B.P.; Banich, M.T.; Heller, W. Trait approach and avoidance motivation: Lateralized neural activity associated with executive function. Neuroimage 2011, 54, 661-670. [CrossRef] [PubMed]

19. Nitschke, J.B.; Heller, W.; Etienne, M.A.; Miller, G.A. Prefrontal cortex activity differentiates processes affecting memory in depression. Biol. Psychol. 2004, 67, 125-143. [CrossRef] 
20. Levin, R.L.; Heller, W.; Mohanty, A.; Herrington, J.D.; Miller, G.A. Cognitive deficits in depression and functional specificity of regional brain activity. Cogn. Ther. Res. 2007, 31, 211-233. [CrossRef]

21. Henriques, J.B.; Davidson, R.J. Left frontal hypoactivation in depression. J. Abnorm. Psychol. 1991, $100,535$. [CrossRef]

22. Heller, W.; Nitschke, J.B.; Etienne, M.A.; Miller, G.A. Patterns of regional brain activity differentiate types of anxiety. J. Abnorm. Psychol. 1997, 106, 376. [CrossRef]

23. Nitschke, J.B.; Heller, W.; Palmieri, P.A.; Miller, G.A. Contrasting patterns of brain activity in anxious apprehension and anxious arousal. Psychophysiology 1999, 36, 628-637. [CrossRef]

24. Roh, S.-C.; Kim, J.S.; Kim, S.; Kim, Y.; Lee, S.-H. Frontal Alpha Asymmetry Moderated by Suicidal Ideation in Patients with Major Depressive Disorder: A Comparison with Healthy Individuals. Available online: http://www.cpn.or.kr/journal/view.html?uid=919\&vmd=Full\& (accessed on 14 November 2019).

25. Klumpp, H.; Deldin, P. Review of brain functioning in depression for semantic processing and verbal fluency. Int. J. Psychophysiol. 2010, 75, 77-85. [CrossRef] [PubMed]

26. Cha, C.B.; Najmi, S.; Park, J.M.; Finn, C.T.; Nock, M.K. Attentional bias toward suicide-related stimuli predicts suicidal behavior. J. Abnorm. Psychol. 2010, 119, 616. [CrossRef] [PubMed]

27. Jollant, F.; Lawrence, N.L.; Olié, E.; Guillaume, S.; Courtet, P. The suicidal mind and brain: A review of neuropsychological and neuroimaging studies. World J. Biol. Psychiatry 2011, 12, 319-339. [CrossRef] [PubMed]

28. Keilp, J.; Gorlyn, M.; Russell, M.; Oquendo, M.; Burke, A.; Harkavy-Friedman, J.; Mann, J. Neuropsychological function and suicidal behavior: Attention control, memory and executive dysfunction in suicide attempt. Psychol. Med. 2013, 43, 539-551. [CrossRef] [PubMed]

29. Jang, K.-I.; Lee, S.; Lee, S.-H.; Chae, J.-H. Frontal alpha asymmetry, heart rate variability, and positive resources in bereaved family members with suicidal ideation after the Sewol ferry disaster. Psychiatry Investig. 2018, 15, 1168. [CrossRef]

30. Sublette, M.E.; Milak, M.S.; Galfalvy, H.C.; Oquendo, M.A.; Malone, K.M.; Mann, J.J. Regional brain glucose uptake distinguishes suicide attempters from non-attempters in major depression. Arch. Suicide Res. 2013, 17, 434-447. [CrossRef]

31. Pu, S.; Nakagome, K.; Yamada, T.; Yokoyama, K.; Matsumura, H.; Yamada, S.; Sugie, T.; Miura, A.; Mitani, H.; Iwata, M. Suicidal ideation is associated with reduced prefrontal activation during a verbal fluency task in patients with major depressive disorder. J. Affect. Disord. 2015, 181, 9-17. [CrossRef]

32. Tsujii, N.; Mikawa, W.; Tsujimoto, E.; Adachi, T.; Niwa, A.; Ono, H.; Shirakawa, O. Reduced left precentral regional responses in patients with major depressive disorder and history of suicide attempts. PLoS ONE 2017, 12, e0175249. [CrossRef]

33. Graae, F.; Tenke, C.; Bruder, G.; Rotheram, M.-J.; Piacentini, J.; Castro-Blanco, D.; Leite, P.; Towey, J. Abnormality of EEG alpha asymmetry in female adolescent suicide attempters. Biol. Psychiatry 1996, 40, 706-713. [CrossRef]

34. Association, A.P. Diagnostic and Statistical Manual of Mental Disorders (DSM-5 $\left.{ }^{\circledR}\right)$; American Psychiatric Pub: Lansing, MI, USA, 2013.

35. Lee, Y.; Song, J. A study of the reliability and the validity of the BDI, SDS, and MMPI-D scales. Korean J. Clin. Psychol 1991, 10, 98-113.

36. Hahn, D.W. Perceived Dimensions of Personality Traits. Korean J. Soc. Personal. Psychol. 1993, 7, $198-211$.

37. Menke, A.; Domschke, K.; Czamara, D.; Klengel, T.; Hennings, J.; Lucae, S.; Baune, B.T.; Arolt, V.; Müller-Myhsok, B.; Holsboer, F. Genome-wide association study of antidepressant treatment-emergent suicidal ideation. Neuropsychopharmacology 2012, 37, 797. [CrossRef] [PubMed]

38. Clarke, D.E.; Colantonio, A.; Rhodes, A.; Conn, D.; Heslegrave, R.; Links, P.; van Reekum, R. Differential experiences during the holocaust and suicidal ideation in older adults in treatment for depression. J. Trauma. Stress 2006, 19, 417-423. [CrossRef] [PubMed]

39. Brzezicka, A.; Kamiński, J.; Kamińska, O.K.; Wołyńczyk-Gmaj, D.; Sedek, G. Frontal EEG alpha band asymmetry as a predictor of reasoning deficiency in depressed people. Cogn. Emot. 2017, 31, 868-878. [CrossRef]

40. RP Alves, M.; Yamamoto, T.; Arias-Carrión, O.; BF Rocha, N.; E Nardi, A.; Machado, S.; Cardoso, A. Executive function impairments in patients with depression. Cns Neurol. Disord. -Drug Targets (Former. Curr. Drug Targets-Cns Neurol. Disord.) 2014, 13, 1026-1040. [CrossRef] 
41. Henry, J.D.; Crawford, J.R. A meta-analytic review of verbal fluency deficits in depression. J. Clin. Exp. Neuropsychol. 2005, 27, 78-101. [CrossRef]

42. Çiçek, M.; Nalçacı, E. Interhemispheric asymmetry of EEG alpha activity at rest and during the Wisconsin Card Sorting Test: Relations with performance. Biol. Psychol. 2001, 58, 75-88. [CrossRef]

43. Arai, H.; Takano, M.; Miyakawa, K.; Ota, T.; Takahashi, T.; Asaka, H.; Kawaguchi, T. A quantitative near-infrared spectroscopy study: A decrease in cerebral hemoglobin oxygenation in Alzheimer's disease and mild cognitive impairment. Brain Cogn. 2006, 61, 189-194. [CrossRef]

44. Kim, T.Y.; Kim, S.Y.; Son, J.E.; Lee, E.A.; Yoo, B.G.; Lee, S.; Hong, T.; Kim, M. Development of the Korean Stroop Test and Study of the Validity and the Reliability. J. Korean Geriatr. Soc. 2004, 8, 233-240.

45. Kane, M.J.; Conway, A.R.; Miura, T.K.; Colflesh, G.J. Working memory, attention control, and the N-back task: A question of construct validity. J. Exp. Psychol. Learn. Mem. Cogn. 2007, 33, 615. [CrossRef]

46. Choi, J.-K.; Kim, J.-M.; Hwang, G.; Yang, J.; Choi, M.-G.; Bae, H.-M. Time-divided spread-spectrum code-based $400 \mathrm{fW}$-detectable multichannel fNIRS IC for portable functional brain imaging. Ieee J. Solid-State Circuits 2016, 51, 484-495.

47. Delpy, D.T.; Cope, M.; van der Zee, P.; Arridge, S.; Wray, S.; Wyatt, J. Estimation of optical pathlength through tissue from direct time of flight measurement. Phys. Med. Biol. 1988, 33, 1433. [CrossRef] [PubMed]

48. Vermeij, A.; Van Beek, A.H.; Rikkert, M.G.O.; Claassen, J.A.; Kessels, R.P. Effects of aging on cerebral oxygenation during working-memory performance: A functional near-infrared spectroscopy study. PLoS ONE 2012, 7, e46210. [CrossRef] [PubMed]

49. Stewart, J.L.; Bismark, A.W.; Towers, D.N.; Coan, J.A.; Allen, J.J. Resting frontal EEG asymmetry as an endophenotype for depression risk: Sex-specific patterns of frontal brain asymmetry. J. Abnorm. Psychol. 2010, 119, 502. [CrossRef] [PubMed]

50. Dudoit, S.; van der Laan, M.J.; Pollard, K.S. Multiple testing. Part I. Single-step procedures for control of general type I error rates. Stat. Appl. Genet. Mol. Biol. 2004, 3, 1-69. [CrossRef]

51. Hoshi, Y.; Kobayashi, N.; Tamura, M. Interpretation of near-infrared spectroscopy signals: A study with a newly developed perfused rat brain model. J. Appl. Physiol. 2001, 90, 1657-1662. [CrossRef]

52. Strangman, G.; Culver, J.P.; Thompson, J.H.; Boas, D.A. A quantitative comparison of simultaneous BOLD fMRI and NIRS recordings during functional brain activation. Neuroimage 2002, 17, 719-731. [CrossRef]

53. Baxter, L.R.; Schwartz, J.M.; Phelps, M.E.; Mazziotta, J.C.; Guze, B.H.; Selin, C.E.; Gerner, R.H.; Sumida, R.M. Reduction of prefrontal cortex glucose metabolism common to three types of depression. Arch. Gen. Psychiatry 1989, 46, 243-250. [CrossRef]

54. Bench, C.J.; Friston, K.J.; Brown, R.G.; Scott, L.C.; Frackowiak, R.S.; Dolan, R.J. The anatomy of melancholia-focal abnormalities of cerebral blood flow in major depression. Psychol. Med. 1992, 22, 607-615. [CrossRef]

55. Gotlib, I.H. EEG alpha asymmetry, depression, and cognitive functioning. Cogn. Emot. 1998, 12, 449-478. [CrossRef]

56. Manna, C.B.; Tenke, C.E.; Gates, N.A.; Kayser, J.; Borod, J.C.; Stewart, J.W.; McGrath, P.J.; Bruder, G.E. EEG hemispheric asymmetries during cognitive tasks in depressed patients with high versus low trait anxiety. Clin. Eeg Neurosci. 2010, 41, 196-202. [CrossRef] [PubMed]

57. Videbech, P.; Ravnkilde, B.; Kristensen, S.; Egander, A.; Clemmensen, K.; Rasmussen, N.A.; Gjedde, A.; Rosenberg, R. The Danish PET/depression project: Poor verbal fluency performance despite normal prefrontal activation in patients with major depression. Psychiatry Res. Neuroimaging 2003, 123, 49-63. [CrossRef]

58. Towers, D.N.; Allen, J.J. A better estimate of the internal consistency reliability of frontal EEG asymmetry scores. Psychophysiology 2009, 46, 132-142. [CrossRef] [PubMed]

59. Allen, J.J.; Urry, H.L.; Hitt, S.K.; Coan, J.A. The stability of resting frontal electroencephalographic asymmetry in depression. Psychophysiology 2004, 41, 269-280. [CrossRef]

60. Coan, J.A.; Allen, J.J. Frontal EEG asymmetry as a moderator and mediator of emotion. Biol. Psychol. 2004, 67, 7-50. [CrossRef]

61. Kawakubo, Y.; Yanagi, M.; Tsujii, N.; Shirakawa, O. Repetition of verbal fluency task attenuates the hemodynamic activation in the left prefrontal cortex: Enhancing the clinical usefulness of near-infrared spectroscopy. PLoS ONE 2018, 13, e0193994. [CrossRef] 
62. Quaresima, V.; Ferrari, M.; Torricelli, A.; Spinelli, L.; Pifferi, A.; Cubeddu, R. Bilateral prefrontal cortex oxygenation responses to a verbal fluency task: A multichannel time-resolved near-infrared topography study. J. Biomed. Opt. 2005, 10, 011012. [CrossRef]

63. Dresler, T.; Schecklmann, M.; Ernst, L.H.; Pohla, C.; Warrings, B.; Fischer, M.; Polak, T.; Fallgatter, A.J. Recovery of cortical functioning in abstinent alcohol-dependent patients: Prefrontal brain oxygenation during verbal fluency at different phases during withdrawal. World J. Biol. Psychiatry 2012, 13, 135-145. [CrossRef]

64. Bisconti, S.; Di Sante, G.; Ferrari, M.; Quaresima, V. Functional near-infrared spectroscopy reveals heterogeneous patterns of language lateralization over frontopolar cortex. Neurosci. Res. 2012, 73, 328-332. [CrossRef]

65. Gable, P.A.; Mechin, N.C.; Hicks, J.A.; Adams, D.L. Supervisory control system and frontal asymmetry: Neurophysiological traits of emotion-based impulsivity. Soc. Cogn. Affect. Neurosci. 2015, 10, 1310-1315. [CrossRef]

66. Rybak, M.; Crayton, J.W.; Young, I.J.; Herba, E.; Konopka, L.M. Frontal alpha power asymmetry in aggressive children and adolescents with mood and disruptive behavior disorders. Clin. Eeg Neurosci. 2006, 37, 16-24. [CrossRef] [PubMed]

67. Corruble, E.; Benyamina, A.; Bayle, F.; Falissard, B.; Hardy, P. Understanding impulsivity in severe depression? A psychometrical contribution. Prog. Neuro-Psychopharmacol. Biol. Psychiatry 2003, 27, 829-833. [CrossRef]

68. Gable, P.A.; Neal, L.B.; Threadgill, A.H. Regulatory behavior and frontal activity: Considering the role of revised-BIS in relative right frontal asymmetry. Psychophysiology 2018, 55, e12910. [CrossRef] [PubMed]

69. Frith, C.; Friston, K.; Liddle, P.; Frackowiak, R. A PET study of word finding. Neuropsychologia 1991, 29, 1137-1148. [CrossRef]

70. Phelps, E.A.; Hyder, F.; Blamire, A.M.; Shulman, R.G. FMRI of the prefrontal cortex during overt verbal fluency. Neuroreport 1997, 8, 561-565. [CrossRef]

71. Zhang, L.; Sun, J.; Sun, B.; Luo, Q.; Gong, H. Studying hemispheric lateralization during a Stroop task through near-infrared spectroscopy-based connectivity. J. Biomed. Opt. 2014, 19, 057012. [CrossRef]

72. Killgore, W.D.; Gruber, S.A.; Yurgelun-Todd, D.A. Depressed mood and lateralized prefrontal activity during a Stroop task in adolescent children. Neurosci. Lett. 2007, 416, 43-48. [CrossRef]

73. Harvey, P.-O.; Fossati, P.; Pochon, J.-B.; Levy, R.; LeBastard, G.; Lehéricy, S.; Allilaire, J.-F.; Dubois, B. Cognitive control and brain resources in major depression: An fMRI study using the n-back task. Neuroimage 2005, 26, 860-869. [CrossRef]

74. Norris, M.P.; Blankenship-Reuter, L.; Snow-Turek, A.L.; Finch, J. Influence of depression on verbal fluency performance. AgingNeuropsychol. Cogn. 1995, 2, 206-215. [CrossRef]

75. Brigadoi, S.; Cooper, R.J. How short is short? Optimum source-detector distance for short-separation channels in functional near-infrared spectroscopy. Neurophotonics 2015, 2, 025005. [CrossRef]

76. Noda, T.; Yoshida, S.; Matsuda, T.; Okamoto, N.; Sakamoto, K.; Koseki, S.; Numachi, Y.; Matsushima, E.; Kunugi, H.; Higuchi, T. Frontal and right temporal activations correlate negatively with depression severity during verbal fluency task: A multi-channel near-infrared spectroscopy study. J. Psychiatr. Res. 2012, 46, 905-912. [CrossRef] [PubMed]

77. Takamiya, A.; Hirano, J.; Ebuchi, Y.; Ogino, S.; Shimegi, K.; Emura, H.; Yonemori, K.; Shimazawa, A.; Miura, G.; Hyodo, A. High-dose antidepressants affect near-infrared spectroscopy signals: A retrospective study. Neuroimage: Clin. 2017, 14, 648-655. [CrossRef] [PubMed]

78. Takizawa, R.; Fukuda, M.; Kawasaki, S.; Kasai, K.; Mimura, M.; Pu, S.; Noda, T.; Niwa, S.-i.; Okazaki, Y.; Joint Project for Psychiatric Application of Near-Infrared Spectroscopy (JPSY-NIRS) Group. Neuroimaging-aided differential diagnosis of the depressive state. Neuroimage 2014, 85, 498-507. [CrossRef] [PubMed]

79. Kohmura, K.; Iwamoto, K.; Aleksic, B.; Sasada, K.; Kawano, N.; Katayama, H.; Noda, Y.; Noda, A.; Iidaka, T.; Ozaki, N. Effects of sedative antidepressants on prefrontal cortex activity during verbal fluency task in healthy subjects: A near-infrared spectroscopy study. Psychopharmacology 2013, 226, 75-81. [CrossRef] [PubMed] 
80. Tsujii, T.; Yamamoto, E.; Ohira, T.; Saito, N.; Watanabe, S. Effects of sedative and non-sedative H 1 antagonists on cognitive tasks: Behavioral and near-infrared spectroscopy (NIRS) examinations. Psychopharmacology 2007, 194, 83-91. [CrossRef] [PubMed]

81. Tsujii, T.; Masuda, S.; Yamamoto, E.; Ohira, T.; Akiyama, T.; Takahashi, T.; Watanabe, S. Effects of sedative and nonsedative antihistamines on prefrontal activity during verbal fluency task in young children: A near-infrared spectroscopy (NIRS) study. Psychopharmacology 2009, 207, 127. [CrossRef] [PubMed] 